\title{
The effect of corneal thickness on intraocular pressure measurement in patients with corneal pathology
}

\author{
A C Browning, A Bhan, A P Rotchford, S Shah, H S Dua
}

Br J Ophthalmol 2004;88:1395-1399. doi: 10.1136/bjo.2003.037887

\begin{abstract}
Background/aim: To compare intraocular pressure (IOP) measurements taken by the Goldmann applanation tonometer, the Tono-Pen and the ocular blood flow pneumotonometer in eyes with varying central corneal thickness $(C C T)$ due to penetrating keratoplasty (PK), keratoconus (KC), and Fuchs' endothelial dystrophy (FED).

Methods: IOP was measured with the Goldmann applanation tonometer, Tono-Pen $\mathrm{XL}$, and $\mathrm{OBF}$ pneumotonometer in 127 eyes with the following corneal abnormalities. There were 56 eyes that had undergone PK, 37 eyes with KC, and 34 eyes with FED. CCT was measured using an ultrasound pachymeter after IOP determinations had been made.

Results: Mean IOP measurements in all three patient groups were significantly higher when measured by OBF pneumotonometer. Linear regression analysis showed that patients with FED had a significant increase in IOP with increasing CCT of $0.18 \mathrm{~mm} \mathrm{Hg} / 10 \mu \mathrm{m}$ using the Goldmann tonometer, $0.15 \mathrm{~mm} \mathrm{Hg} / 10 \mu \mathrm{m}$ with the Tono-Pen, and $0.26 \mathrm{~mm} \mathrm{Hg} /$ $10 \mu \mathrm{m}$ with the OBF pneumotonometer. In patients with KC and after PK, linear regression analysis did not show a significant effect of CCT on IOP. A multivariate linear regression model controlling for age, sex, graft size, and patient group, showed that the effect of CCT on IOP for Tono-Pen $(0.13 \mathrm{~mm} \mathrm{Hg} / 10 \mu \mathrm{m} \mathrm{CCT})$ and Goldmann $(0.14 \mathrm{~mm} \mathrm{Hg} / 10 \mu \mathrm{m} \mathrm{CCT)} \mathrm{were} \mathrm{significantly} \mathrm{lower} \mathrm{than}$ for the OBF pneumotonometer $(0.26 \mathrm{~mm} \mathrm{Hg} / 10 \mu \mathrm{m}$ CCT). Conclusions: This study found that mean IOP measurements using the $\mathrm{OBF}$ pneumotonometer were significantly higher than those made using the Goldmann applanation tonometer or Tono-Pen in eyes with a variety of cornel pathologies. The $\mathrm{OBF}$ pneumotonometer was found to be most affected by variation in CCT. For all three instruments, the relation between IOP and CCT depended on the corneal pathology and was greatest for FED.
\end{abstract}

$\mathrm{T}$ he measurement of intraocular pressure (IOP) in patients with corneal abnormalities is problematic because of the effect of corneal thickness and ocular surface disease on measurement techniques. ${ }^{1}$ Glaucoma or ocular hypertension may coexist in patients with structurally abnormal corneas such as keratoconus or Fuchs endothelial dystrophy and in patients who have undergone penetrating keratoplasty or refractive surgery. ${ }^{2}$ After penetrating keratoplasty, up to $30 \%$ of patients may have raised IOP or glaucoma, risking both optic nerve damage and graft failure. ${ }^{3}$ It is therefore important that reliable measurement of IOP is made in these patients to assist in the diagnosis and monitoring of treatment.

In 1957 Goldmann first suggested that IOP measurement by applanation tonometry could be affected by central corneal thickness (CCT). ${ }^{4}$ Since then other workers have confirmed this and defined the effect. ${ }^{156}$ They found that measurement of IOP in patients with thin corneas tended to be underestimated while with thick corneas the opposite occurred. Other workers have attempted to circumvent the effect of CCT by utilising other methods of IOP measurement such as the Tono-Pen. ${ }^{7}$ This is a small computerised hand held instrument which operates on the same principle as the MacKay-Marg electronic applanation tonometer and is thought to be less affected by CCT and ocular surface abnormalities. $^{7}$

Recently, the OBF pneumotonometer (OBF Labs, Malmesbury, Wilts, UK) now being marketed as the ocular blood flow analyser (Paradigm Medical Industries, Salt Lake City, UT, USA) has become available to measure IOP. The instrument measures IOP by contact pneumotonometry and is based on an instrument first developed by Langham and co-workers. ${ }^{89}$ Theoretically, it has been claimed that the calculation of IOP by pneumotonometers is not affected by CCT, as flexural rigidity of the cornea can be ignored.$^{10}$ Recent studies have shown that the OBF pneumotonometer produces similar results to both manometric and Goldman applanation techniques. ${ }^{1-14}$ However, other workers have questioned its usefulness in a clinical environment owing to its poor intra-individual repeatability. ${ }^{15}$

The aim of this study was to determine the effect of CCT on IOP measurements made using the Goldmann applanation tonometer, Tono-Pen, and the OBF pneumotonometer in patients with keratoconus (KC), Fuchs' endothelial dystrophy (FED), and after penetrating keratoplasty (PK).

\section{METHODS}

Data were obtained from patients with KC, FED, and after PK who were attending a university hospital corneal clinic. IOP was measured randomly by alternate allocation using the Goldmann applanation tonometer, Tono-pen XL (Mentor Ophthalmics Inc, Norwell, MA, USA), and the OBF pneumotonometer (marketed by Paradigm Medical Industries, Salt Lake City, UT, USA) in close succession on each patient. After IOP measurements had been made, CCT was measured using ultrasound pachymetry. All patients recruited for the study had less than 3 dioptres of astigmatism. The research had the approval of the local research and ethics committee and followed the tenets of the declaration of Helsinki. All measurements were taken by experienced ophthalmologists after gaining informed consent.

Measurements on each individual eye were performed in close succession at the same sitting by a single ophthalmologist after the cornea was anaesthetised with unpreserved lidocaine $4 \%$ combined with fluorescein $0.25 \%$ (Chauvin Pharmaceuticals Ltd, Montpellier, France) and patients were instructed to relax, sit upright, breathe normally, and look

Abbreviations: CCT, central corneal thickness; FED, Fuchs' endothelial dystrophy; IOP, intraocular pressure; $\mathrm{KC}$, keratoconus; PK, penetrating keratoplasty 
Table 1 Descriptive statistics of the study population

\begin{tabular}{lllll}
\hline Diagnosis & $\begin{array}{l}\text { Penetrating } \\
\text { keratoplasty }\end{array}$ & Keratoconus & $\begin{array}{l}\text { Fuchs endothelial } \\
\text { dystrophy }\end{array}$ & All \\
\hline $\begin{array}{l}\text { No of eyes } \\
\text { Mean age }\end{array}$ & 56 & 37 & 34 & 127 \\
$\begin{array}{l}\text { (range) } \\
\text { Male }(\%)\end{array}$ & $51.3(20-80)$ & $30.9(18-51)$ & $65.8(36-91)$ & $49.3(18-91)$ \\
\hline
\end{tabular}

straight ahead. Clothing that was tight fitting at the neck was loosened. Goldmann applanation tonometry was performed on the central cornea of each eye three times and the mean result was recorded. Tono-Pen tonometry was performed on the central cornea using an instrument calibrated according to the manufacturer's instructions. All measurements were made with a disposable latex cover over the tip, which was renewed after each patient. At least five IOP readings were taken with the Tono-Pen pen and the instrument calculated mean IOP was accepted if the standard error of the mean was $\leqslant 5 \%$.

The OBF pneumotonometer instrument consists of a $5 \mathrm{~mm}$ diameter plastic tip covered by a membrane that is mounted on a frictionless bearing. Air at an elevated constant pressure flows down the centre of the probe and pushes against this membrane. The membrane deforms the cornea and air escapes into the atmosphere up the outside of the probe. The size of the gap created for the air to escape under the membrane is measured indirectly by the air flow rate at equilibrium and this is converted to the IOP opposing the deformation of the cornea. The instrument automatically collects data (200 readings/second) over a period of 20 seconds and the mean IOP is displayed on an LCD. Each OBF IOP measurement was therefore a mean of 4000 readings. Pneumotonometry was performed upright with a slit lamp mounted probe. Each day before use, the air pressure generated by the instrument was checked with a manometer and was calibrated according to the manufacturer's instructions. Patients were instructed to look at the red fixation target within the probe. The probe tip was applied to the central cornea and when correctly aligned a whistling noise was heard. The probe was kept applied to the cornea until five pulses of equal amplitude were recorded. The mean IOP was calculated by the instrument and displayed on a liquid crystal display. After all IOP measurements had been made, each eye had its CCT measured with a Tomey SP-2000 ultrasonic pachymeter (Tomey Corp, Cambridge, MA, USA). In this study, the grading of the corneal oedema or keratoconus was not assessed. Because of the variability in size, shape, and location of the cone in patients with $\mathrm{KC}$, the geometric centre of the cornea was chosen for all measurements. In patients with corneal grafts, the time from grafting to the measurement of IOP was recorded as was the size of the donor graft used. However, the type and number of corneal sutures was not recorded

For each instrument, the mean IOP was calculated in each pathological group. A regression coefficient $(\mathrm{mm} \mathrm{Hg} / \mathrm{l} 0 \mu \mathrm{m})$ and a regression coefficient adjusted for diagnosis was calculated for each instrument and corneal pathology using SPSS for Windows, Version 10.0 (SPSS Inc, Chicago, IL, USA). Scatter plots of IOP against CCT were drawn for each instrument in patients with FED.

\section{RESULTS}

A total of 127 eyes of 127 patients with abnormal corneas were examined as part of the study. In patients with bilateral corneal pathology only the right eye was included in the analysis. There were 56 patients of mean age 51.3 years who had undergone penetrating keratoplasty. Thirty seven patients had a diagnosis of keratoconus with a mean age of 30.9 years. Thirty four patients had Fuchs' endothelial dystrophy with a mean age of 65.8 years.

A summary of the patient's descriptive statistics is shown in table 1. Patients in the PK subgroup had a mean follow up period of 58.1 months from the time of the PK to the time IOP measurement (range 3-360 months). The mean size of the donor grafts was $8.1 \mathrm{~mm}$ (range 7.1-8.75 mm).

The mean CCT and measured IOP using each different instrument for each of the three patient groups are shown in table 2 The IOP readings taken with the OBF pneumotonometer were significantly higher and the SD larger than those made with the Goldmann or Tono-Pen tonometers in each of

Table 2 Mean (SD) CCT and IOP for each patient group for measurements taken by Goldmann applanation tonometer, TonoPen, and OBF pneumotonometer

\begin{tabular}{lllll}
\hline Diagnosis & CCT $(\mu \mathrm{m})($ range) & Goldmann $(\mathbf{m m ~ H g})($ range) & Tono-Pen $(\mathbf{m m ~ H g})($ range) & OBF $(\mathbf{m m} \mathrm{Hg})(\mathrm{range})$ \\
\hline FED & $624(107)(512-947)$ & $14.3(4.0)(8-27)$ & $13.1(3.6)(7-23)$ & $15.9(5.2)(8.9-28.4)$ \\
KC & $455(67)(330-587)$ & $10.5(2.2)(7-15)$ & $10.9(2.7)(6-17)$ & $11.4(3.2)(6.5-20.0)$ \\
PK & $557(65)(341-746)$ & $14.9(5.5)(6-28)$ & $15.2(4.5)(7-25)$ & $18.1(6.2)(6.5-34.3)$ \\
All & $545(101)(330-947)$ & $13.4(4.8)(6-28)$ & $13.4(4.2)(6-25)$ & $15.6(5.9)(6.5-34.3)$ \\
\hline
\end{tabular}

Table 3 Increase in IOP $(\mathrm{mm} \mathrm{Hg}) / 10 \mu \mathrm{m}$ increase in CCT

\begin{tabular}{llll}
\hline Diagnosis & Goldmann $(95 \% \mathrm{Cl})$ & Tono-Pen $(95 \% \mathrm{Cl})$ & OBF (95\% CI) \\
\hline All & $0.18(0.10$ to 0.25$)(p \leqslant 0.001)$ & $0.10(0.03$ to 0.17$)(p=0.007)$ & $0.22(0.12$ to 0.32$)(p=0.001)$ \\
FED & $0.18(0.06$ to 0.30$)(p=0.005)$ & $0.15(0.04$ to 0.26$)(p=0.007)$ & $0.25(0.11$ to 0.40$)(p=0.001)$ \\
KC & $0.01(-0.1$ to 0.13$)(p=0.80)$ & $-0.01(-0.15$ to 0.12$)(p=0.84)$ & $-0.03(-0.20$ to 0.13$)(p=0.69)$ \\
PK & $0.11(-0.12$ to 0.34$)(p=0.33)$ & $-0.05(-0.24$ to 0.14$)(p=0.59)$ & $0.14(-0.11$ to 0.40$)(p=0.27)$
\end{tabular}


Table 4 Increase in IOP $(\mathrm{mm} \mathrm{Hg})$ per $10 \mu \mathrm{m}$ increase in CCT adjusted for patient group, age, graft size, duration of follow up, and sex by multivariate linear regression

\begin{tabular}{llll}
\hline & Goldmann $(95 \% \mathrm{Cl})$ & Tono-Pen $(95 \% \mathrm{Cl})$ & OBF $(95 \% \mathrm{Cl})$ \\
\hline $\begin{array}{l}\text { Regression } \\
\text { coefficient }\end{array}$ & $0.14(0.06$ to 0.23$)$ & $0.13(0.06$ to 0.20$)$ & $0.26(0.17$ to 0.35$)(p \leqslant 0.01)$ \\
\hline
\end{tabular}

the three patient groups (table 2). OBF pneumotonometer values were least comparable with the other two methods in the PK group, in which the mean OBF IOP estimate was $3.2 \mathrm{~mm} \mathrm{Hg}$ higher than the mean Goldmann IOP reading $(\mathrm{p}<001$, paired Student's $t$ test $)$ and $2.9 \mathrm{~mm} \mathrm{Hg}$ higher than the mean Tono-Pen IOP $(\mathrm{p}<0.001)$.

Linear regression analysis was performed to determine the changes in measured IOP $(\mathrm{mm} \mathrm{Hg})$ for a given increase in CCT $(10 \mu \mathrm{m})$. These results are shown in table 3 . For each of the three patient groups, OBF pneumotonometer estimates of IOP were more sensitive to changes in CCT than either the Tono-Pen or Goldmann tonometers.

However, the strength of the relation between IOP readings and CCT was dependent on patient group. For all three instruments, the effect of CCT on IOP readings was only statistically significant in one patient group-those with FED. Scatter plots of IOP against CCT for each instrument in patients with FED are shown in figure 1. Too few data points were present above a CCT of $720 \mu \mathrm{m}$ to determine if the effect was linear for each instrument at high CCT values. In order to control for the influence of patient group on the relation between IOP and CCT, a multivariate linear regression model taking into account age, sex, graft size, duration of follow up, and patient group was used (table 4). The regression coefficients for Tono-Pen $(0.13 \mathrm{~mm} \mathrm{Hg} / 10 \mu \mathrm{m}$ CCT $)$ and Goldmann $(0.14 \mathrm{~mm} \mathrm{Hg} / 10 \mu \mathrm{m} \quad \mathrm{CCT})$ were significantly lower $(p \leqslant 0.01)$ than for the OBF pneumotonometer (0.26 mm Hg/10 $\mu \mathrm{m} \mathrm{CCT)} \mathrm{(see} \mathrm{table} \mathrm{4).} \mathrm{Age,} \mathrm{sex,} \mathrm{graft} \mathrm{size,}$ and duration of follow up were found not to have a significant effect on the measurement of IOP with any of the instruments.

\section{DISCUSSION}

The accurate measurement of IOP is important in patients with abnormal corneas. Measurement of true IOP by manometry is impractical to carry out in a routine clinical setting and is not without risk. In lieu of true clinic based IOP measurements, Goldmann applanation tonometry has been accepted as the gold standard technique despite the readings being affected by a number of variables. ${ }^{16}$

Studies have shown a relation between CCT and IOP in eyes with normal and abnormal corneas, when measured by Goldmann applanation tonometry. ${ }^{17}$ This has led to the association of increased corneal thickness and falsely elevated tonometer readings. In previous studies an increase of between 0.11 and $0.71 \mathrm{~mm} \mathrm{Hg}$ has been reported for every $10 \mu \mathrm{m}$ of deviation from a normal CCT measurement, albeit in structurally normal corneas. ${ }^{5618}$ In this study the Goldmann applanation tonometer showed an increase of IOP of between 0.014 and $0.179 \mathrm{~mm} \mathrm{Hg} / 10 \mu \mathrm{m}$ of CCT depending on the underlying corneal pathology.

Different types of tonometer have been developed which it is claimed are less affected by corneal thickness and ocular surface abnormalities. One such type is the Mackay-Marg instrument. This is an electronic applanation tonometer consisting of a hand held probe connected to a position transducer. ${ }^{19}$ While there was an excellent agreement between this instrument and manometric readings of IOP in patients ${ }^{20}$ and owl monkeys ${ }^{21}$ with irregular, oedematous,
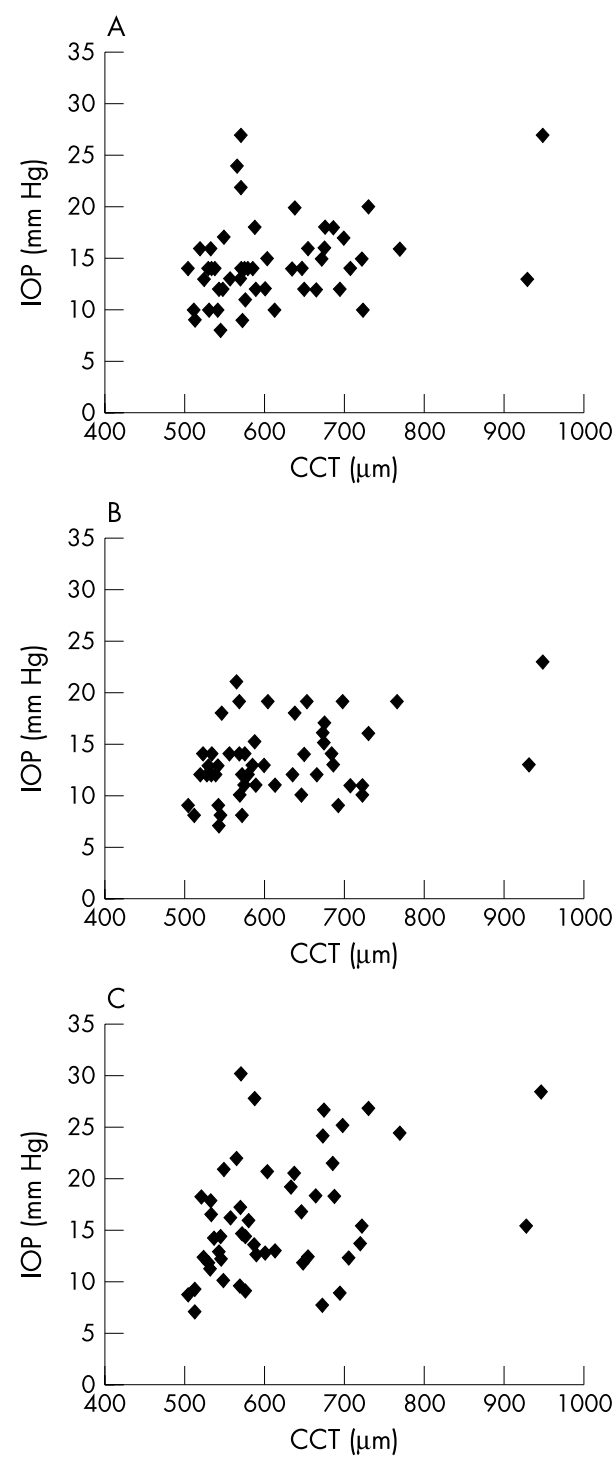

Figure 1 Scatter plots of IOP against CCT using the (A) Goldmann applanation tonometer, (B) Tono-Pen, and (C) OBF pneumotonometer in patients with FED.

and scarred corneas, the instrument is cumbersome to operate outside of the laboratory and at present is not commercially available. However, the hand held Tono-Pen is widely available and is based on the Mackay-Marg principle. It is easy to use, portable, and produces results similar to the Mackay-Marg tonometer in the presence of corneal surface irregularities. ${ }^{7}$ Unlike the Mackay-Marg instrument, however, studies have shown that the Tono-Pen may be affected by corneal thickness and the presence of calcium or cyanoacrylate glue. ${ }^{22}$ A study of patients with healthy corneas showed an increase of IOP of $0.29 \mathrm{~mm} \mathrm{Hg} / 10 \mu \mathrm{m}$ CCT increase in males and $0.12 \mathrm{~mm} \mathrm{Hg} / 10 \mu \mathrm{m}$ in females. ${ }^{23}$ In a 
different study, in a group of patients who had undergone penetrating keratoplasty, the IOP was significantly overestimated using the Tono-Pen when compared with the Goldmann technique, with the greatest mean difference at low IOP readings $(<9 \mathrm{~mm} \mathrm{Hg}) .{ }^{24} \mathrm{CCT}$ was not measured in this study with only the presence or absence of corneal oedema being noted. The results of the current study show that the Tono-Pen readings do not vary significantly with CCT in eyes having undergone penetrating keratoplasty or in those with KC. In patients with Fuchs' endothelial dystrophy, however, readings from the Tono-pen were significantly affected by CCT.

The OBF pneumotonometer is based on a model described by Langham et al. ${ }^{9}$ Previous studies with the instrument in patients with normal corneas have shown a correlation coefficient of between 0.77 and 0.95 when compared with the Goldmann applanation tonometer. ${ }^{1325}{ }^{26}$ It is claimed by the manufacturers to be unaffected by corneal thickness based on the measurement of IOP using a similar instrument before and after excimer photorefractive keratectomy. ${ }^{26}{ }^{27}$ In the current study, linear regression analysis of the three different instruments showed that IOP readings by the OBF pneumotonometer were most affected by the variations in CCT. The instrument also had the highest mean IOP for all patient groups examined. The latter finding is in agreement with previous studies of contact pneumotonometers, which found the method to significantly overestimate IOP when compared with applanation techniques. ${ }^{6} 28$

The Imbert-Fick law on which Goldmann applanation tonometry is based does not take account of corneal thickness as it assumes measurements are made on a cornea of standard thickness $(500 \mu \mathrm{m}) .^{30}$ Similarly, the mathematical derivation of IOP using the pneumotonometer does not include corneal thickness. It is stated that flexural rigidity of the cornea cancels out in the final equation so it need not be considered. ${ }^{31}$ With both of these instruments, our study shows that CCT clearly does have an effect on measured IOP in patients with abnormal corneas. Similarly, corneal rigidity was not considered in the mathematical derivation of IOP with the Mackay-Marg tonometer or Tono-Pen. In this case, the inventors of the instrument suggest that the small size of the applanation tip negates for extraneous factors and need not be considered. ${ }^{19}$ Our data do not corroborate this, however. Interestingly, the Goldmann applanation tonometer has a diameter of contact of $3.06 \mathrm{~mm}$ when applanation occurs despite a tip diameter of approximately $8 \mathrm{~mm}$. The diameter of contact for the Tono-Pen and OBF pneumotonometer at the point of applanation is unknown; however, the instruments have tip diameters of approximately $3 \mathrm{~mm}$ and $5 \mathrm{~mm}$ respectively. The effect of the tip diameter of each instrument on the measurement of IOP could therefore not be assessed. However, because the minimum graft diameter was $7.1 \mathrm{~mm}$ (mean $8.1 \mathrm{~mm}$ ), graft size (and probably the presence of sutures) would be unlikely to interfere with the measurement of IOP.

While the current study did not have a control group of patients with normal corneas for comparison, the authors have recently published the results of a study using the same instruments as used in the current study but with a population of patients with normal corneas. ${ }^{6}$ In keeping with the results of the current study, the previous study conducted on normal corneas also found that the OBF pneumotonometer was most affected by CCT $(0.28 \mathrm{~mm} \mathrm{Hg} / 10 \mu \mathrm{m})$, a value very similar to the current study $(0.26 \mathrm{~mm} \mathrm{Hg} / \mathrm{l} 0 \mu \mathrm{m})$.

Ultrasonic pachymetry is a widely used technique for the measurement of corneal thickness. Although many different models are available, they all work on the same underlying principle of the recording of a time difference between a reflection from the anterior and posterior surfaces of the cornea. Studies have shown a high degree of intraobserver and interobserver reproducibility for a given instrument and high reliability coefficients between different instruments. ${ }^{32-36}$ In contrast, significant differences between ultrasonic and optical pachymeters have been found with latter producing generally higher CCT values. ${ }^{1}$ This makes comparison of data between different methods problematic. For the purposes of this study, however, a single ultrasonic pachymeter was used that relies on a technique that has been shown to be both accurate and reliable. ${ }^{32-36}$ The effect of CCT on IOP measurement between different tonometers is therefore unlikely to be affected by the specific pachymeter used for this study.

We acknowledge that measuring CCT after all the IOP measurements had been made may have affected the CCT reading. However, if CCT had been measured first, it may have artificially lowered the IOP. ${ }^{37}$ Also, the fact that the degree of corneal oedema or the stage of keratoconus was not assessed in this study may be a limitation.

While CCT did have a demonstrable effect on the estimation of IOP, the cause of the underlying corneal pathology also appeared to have a role. In eyes with $\mathrm{KC}$ or after PK, no statistically significant relation between CCT and IOP was seen for any of the three instruments.. IOP readings were most affected by CCT in FED with a significant increase in IOP with increasing corneal thickness. This effect may be related to the changes in corneal rigidity caused by the underlying disease and/or abnormal stromal/epithelial hydration. Interestingly, Moses described the apparent underestimation of IOP in cannulated postmortem eyes with acutely thickened oedematous previously normal corneas and attributed this to the ease of corneal deformation or applanation..$^{38}$ This suggests that other factors aside from hydration affect the corneal rigidity in patients with FED. The specific effects of FED on the measurement of IOP therefore warrant further investigation. Each instrument, therefore, may be affected by corneal rigidity by differing degrees, which may be independent of the CCT, but nevertheless could affect the measured IOP. Outside this study, the effect of structural corneal changes may also have possible ramifications for the measurement of IOP after corneal excimer laser surgery and again warrants further investigation.

In summary, this study found that IOP measured using the OBF pneumotonometer was higher than that made using Goldmann or Tono-Pen tonometers in eyes with a variety of corneal pathologies. Of the three instruments, IOP measured with the OBF pneumotonometer was most affected by variation in CCT. The relation between IOP and CCT depended on the corneal pathology and this was greatest in FED. The effect may not be singularly related to CCT, but to additional factors related to specific corneal pathologies.

\section{ACKNOWLEDGEMENTS}

SS was the Vision Express Fellow in cornea and contact lens, University of Nottingham, during this study.

\section{Authors' affiliations}

A C Browning, A Bhan, A P Rotchford, S Shah, H S Dua, Division of Ophthalmology and Visual Sciences, University Hospital, Queen's Medical Centre, Nottingham NG7 2UH, UK

S Shah, Birmingham and Midlands Eye Centre, City Hospital, Birmingham, UK

Commercial relationships: none.

Correspondence to: Professor Harminder S Dua, Division of Ophthalmology and Visual Sciences, University Hospital, Queen's Medical Centre, Nottingham NG7 2UH, UK; harminder.dua@ nottingham.ac.uk

Accepted for publication 20 February 2004 


\section{REFERENCES}

1 Doughty MJ, Zaman ML. Human corneal thickness and its impact on intraocular pressure measures: a review and meta-analysis approach. Surv Ophthalmol 2000;44:367-408.

2 Ayyala RS. Penetrating keratoplasty and glaucoma. Surv Ophthalmol 2000;45:91-105

3 Goldberg DB, Schazlin DJ, Brown SI. Incidence of increased intraocular pressure after keratoplasty. Am J Ophthalmol 1981;92:372-7.

4 Goldmann H, Schmidt T. Uber applanationstonometrie. Ophthalmologie 1957; 134:221-42.

5 Ehlers N, Bransen T, Sperling S. Applanation tonometry and central corneal thickness. Acta Ophthalmol 1975;53:34-43.

6 Bhan A, Browning AC, Shah S, et al. Effect of corneal thickness on intraocular pressure measurements with the pneumotonometer, Goldmann applanation tonometer and Tono-pen. Invest Ophthalmol Vis Sci 2002;43:1389-92.

7 Rootman DS, et al. Accuracy and precision of the Tono-pen in measuring intraocular pressure after keratoplasty and epikeratophakia and in scarred corneas. Arch Ophthalmol 1988;106:1697-700.

8 Quigley HA, Langham ME. Comparative intraocular pressure measurements with the pneumotonograph and Goldmann tonometer. Am J Ophthalmol 1975;80:266-73.

9 Langham ME, McCarthy E. A rapid pneumatic applanation tonometer. Comparative findings and evaluation. Arch Ophthalmol 1968:79:389-99.

10 Walker RE, Litovitz TL. An experimental and theoretical study of the pneumatic tonometer. Exp Eye Res 1972;13:14-23.

11 Chidlow G, Nash MS, Crowhurst C, et al. The ocular blood flow tonograph: a new instrument for the measurement of intraocular pressure in rabbits. Exp Eye Res 1996;63:463-9.

12 Bafa M, Lambrinakis I, Dayan M, et al. Clinical comparison of the measurement of the IOP with the ocular blood flow tonometer, the Tonopen XL and the Goldmann applanation tonometer. Acta Ophthalmol Scand 2001;79:15-18.

13 Yang YC, Illango B, Cook A, et al. Intraocular pressure and pulse rate measurement by the $\mathrm{OBF}$ tonograph-comparison to reference instruments. Ophthal Physiol Opt 2000;20:401-7.

14 Spraul CW, Lang GE, Ronzani M, et al. Reproducibility of measurements with a new slit lamp-mounted ocular blood flow tonograph. Graefes Arch Clin Exp Ophthalmol 1998;236:274-9.

15 Bhan A, Bhargava J, Vernon SA, et al. Repeatability of ocular blood flow pneumotonometry. Ophthalmology 2003;110:1551-4.

16 Whitacre MM, Stein R. Sources of error with use of Goldmann-type tonometers. Surv Ophthalmol 1993;38:1-30.

17 Patel S, McLaughlin JM. Effects of central corneal thickness on measurement of intra-ocular pressure in keratoconus and post keratoplasty. Ophthalmic Physiol Opt 1999;19:236-41.

18 Shah S, Chatterjee A, Mathai M, et al. Relationship between corneal thickness and measured intraocular pressure in a general ophthalmology clinic. Ophthalmology 1999;106:2154-60.
19 Mackay RS, Marg E, Oechsli R. Automatic tonometer with exact theory: various biological applications. Science 1960;131:1668-9.

20 Kaufmann HE, Wind CA, Waltman SR. Validity of Mackay-Marg electronic applanation tonometer in patients with scarred irregular corneas. Am J Ophthalmol 1970;69:1003-7.

21 McMillan F, Forster RK. Comparison of Mackay-Marg, Goldmann and Perkins tonometers in abnormal corneas. Arch Ophthalmol 1975;93:420-4.

22 Azuara-Blanco A, Bhojani TK, Sarhan AR, et al. Tono-pen determination of intraocular pressure in patients with band keratopathy or glued cornea. Br J Ophthalmol 1998;82:634-6.

23 Dohadwala AA, Munger R, Damji KF. Positive correlation between Tono-pen intraocular pressure and central corneal thickness. Ophthalmology 1998; 105: 1849-54.

24 Geyer O, Mayron Y, Loewenstein A, et al. Tono-pen tonometry in normal and in post-keratoplasty eyes. Br J Ophthalmol 1992;76:538-40.

25 Esgin H, Alimgil ML, Erda S. Clinical comparison of the ocular blood flow tonograph and the Goldmann applanation tonometer. Eur J Ophthalmol 1998:8:162-6.

26 Tuunanen TH, Hamalainen $\mathrm{P}$, Mali $M$, et al. Effect of photorefractive keratectomy on the accuracy of pneumatonometer readings in rabbits. Invest Ophthalmol Vis Sci 1996;37:1810-14.

27 Abbasoglu OE, Bowman W, Cavanagh D, et al. Reliability of intraocular pressure measurements after myopic excimer photorefractive keratectomy. Ophthalmology 1998;105:2193-6.

28 Menage MJ, Kaufmann PL, Croft MA, et al. Intraocular pressure measurement after penetrating keratoplasty: minified Goldmann applanation tonometer, pneumatonometer, and Tono-pen versus manometry. Br J Ophthalmol 1994;78:671-6.

29 Kaufmann HE. Pressure measurement: which tonometer? Invest Ophthalmol 1972;11:80-5.

30 Glouster J, Perkins ES. The validity of the Imbert-Fick law as applied to applanation tonometry. Exp Eye Res 1963;2:274-83.

31 Silver DM, Farrell RA. Validity of pulsatile ocular blood flow measurements. Surv Ophthalmol 1994;38(suppl):S72-80.

32 Miglior S, Albe E, Guareschi M, et al. Intraobserver and interobserver reproducibility in the evaluation of ultrasonic pachymetry measurements of central corneal thickness. Br J Ophthalmol 2004;88:174-7.

$33 \mathrm{Salz} \mathrm{JJ}$, Azen SP, Berstein J, et al. Evaluation and comparison of sources of variability in the measurement of corneal thickness with ultrasonic and optical pachymeters. Ophthalmic Surg 1983;14:750-4.

34 Wheeler NC, Morantes CM, Kristensen RM, et al. Reliability coefficients of three corneal pachymeters. Am J Ophthalmol 1992;113:645-51.

35 Marsich MW, Bullimore MA. The repeatability of corneal thickness measures. Cornea 2000;19:792-5.

36 Thornton SP. A guide to pachymeters. Ophthalmic Surg 1984;15:993-5.

37 Wilke K. Effects of repeated tonometry: genuine and sham measurements. Acta Ophthalmol (Copenh) 1972;50:574-82.

38 Moses RA. The Goldmann applanation tonometer. Am J Ophthalmol 1958;46:865-9. 